\title{
Anticorpos anticardiolipinas em úlceras de perna
}

\section{Anticardiolipin antibodies in leg ulcers}

Thelma laroka Skare ${ }^{1}$; Carmen Autralia Paredes Marcondes Ribas ${ }^{2}$; Osvaldo Malafaia, ECBC-PR²; Jurandir Marcondes Ribas Filho, TCBC-PR²; Paulo Afonso Nunes Nassif, TCBC-PR²; Marcelo Mazza do Nascimento²; Vinícius Ribas Carvalho Duarte FonseCa ${ }^{1}$

\section{R E S U M O}

\begin{abstract}
Objetivo: Verificar a prevalência de anticorpos anticardiolipinas IgG e IgM em pacientes com úlcera de perna e se os seus portadores podem ser identificados clinicamente. Métodos: Estudaram-se 151 pacientes com úlcera de perna (81 venosas, 50 diabéticas e 20 arteriais) e 150 controles. Pesquisou-se, nos dois grupos, a presença de anticorpos anticardiolipina lgG e lgM pelo método de ELISA. No grupo úlcera foram coletados dados demográficos dos pacientes, de tamanho e número de úlceras e gravidade da dor medido por escala visual analógica. Os dados obtidos foram agrupados em tabelas de frequência e contingência. Adotou-se significância de 5\%. Resultados: Encontrou-se prevalência de anticorpos anticardiolipina de $7.2 \%(n=12)$ no grupo com úlceras e de $1.3 \%(n=2)$ no controle $(p=0.01)$. Comparando-se a prevalência dos anticorpos anticardiolipina nos diferentes tipos de úlcera verificou-se aumento nas de origem venosa $(p=0.02)$ e diabéticas $(p=0.01)$, mas não nas arteriais $(p=0.31)$ em relação à população controle. As úlceras de perna anticardiolipinas positivas não diferiram daquelas sem anticardiolipinas quanto a tamanho da ferida $(p=0.6)$; gravidade da dor $(p=0.67)$, número médio de úlceras $(p=0.38)$, tempo de duração de doença $(p=0.59)$, gênero do paciente $(p=0.98)$ e história de trombose prévia $(p=0.69)$. Conclusão: Existe aumento de prevalência de anticorpos anticardiolipinas nos portadores de úlceras de perna venosas e diabéticas, mas não nas arteriais. As características clínicas das úlceras anticardiolipinas positivas não auxiliam na identificação desses pacientes.
\end{abstract}

Descritores: Úlcera da Perna. Insuficiência venosa. Úlcera cutânea. Pé diabético. Anticorpos Anticardiolipina.

\section{INTRODUÇÃO}

Ú ceras de perna são entidades clínicas comuns, de difícil tratamento e que contribuem de maneira substancial para a perda de qualidade de vida de seu portador. Essas úlceras frequentemente são dolorosas, diminuem a capacidade de deambulação e independência do paciente, gerando desemprego com perdas econômicas e baixa auto-estima. Causam ainda isolamento social devido à sua aparência e odor desagradáveis'. Apesar de todas essas repercussões, as úlceras de perna não são valorizadas adequadamente sendo o seu cuidado relegado, muitas vezes a um segundo plano. Parte dessa atitude advém do fato de que seu tratamento é difícil. Elas são rebeldes às terapêuticas usadas, cicatrizam com lentidão e reabrem com grande facilidade ${ }^{1}$.

Tratar adequadamente qualquer doença pressupõe que seus mecanismos etiopatogênicos sejam esclarecidos para que a terapêutica possa ser dirigida corretamente contra o elemento causal. Com úlceras de perna isso não é diferente. Muito dos seus mecanismos fisiopatológicos já foram estudados e são conhecidos; todavia, fenômenos do microambiente tecidual só recentemente têm merecido a devida atenção. Dentre as várias investigações feitas a nível molecular, destacam-se as relacionadas à hipercoagulabilidade. Deficiências de proteína C, S e antitrombina III, alterações genéticas do gene da protrombina e do fator $V$ de Leiden estão entre os defeitos da coagulação já identificados nesses pacientes ${ }^{2}$. É neste contexto que se insere a participação dos anticorpos antifosfolípides.

Anticorpos antifosfolípides formam um grupo de auto-anticorpos dirigidos contra fosfolipídios de carga negativa responsáveis pela causa mais comum de trombofilia adquirida ${ }^{3}$. Fazem parte desse conjunto, os anticorpos anticardiolipinas ( $\mathrm{aCl}$ ) IgG e $\operatorname{lgM}$, o lúpus anticoagulante (LAC) e o anticorpo contra $\beta 2$-glicoproteina $\mathrm{I}^{3}$.

No espectro clínico da síndrome dos anticorpos antifosfolípides (SAF) também são encontradas úlceras de perna. Reconhecer que úlcera de perna é parte da SAF é tarefa fácil quando a clínica é bem estabelecida. Entretanto, em situações subclínicas, essa identificação pode passar despercebida.

A literatura médica inclui vários estudos, feitos principalmente em pacientes com úlceras venosas e diabéticas, nos quais a prevalência desses anticorpos foi maior do que na população geral ${ }^{4}$. Mackenzie et al. ${ }^{2}$ estudando 88 pacientes com diagnóstico de úlcera venosa demonstraram a existência de desordens de coagulação em 36 (41\%) deles. ACls estavam presentes em $14 \%$ dos casos. Alagözlü

Trabalho realizado no Programa de Pós-Graduação em Princípios da Cirurgia da Faculdade Evangélica do Paraná, Curitiba, PR, Brasil.

1. Mestre do Programa de Pós-Graduação em Princípios da Cirurgia, PR - BR; 2. Doutor, Professor Permanente do Programa de Pós-Graduação em Princípios da Cirurgia, PR - BR. 
et al. ${ }^{4}$ estudando 70 pacientes com diabete melito tipo 2 (35 sem úlceras e 35 com úlceras de pé), encontrou maior prevalência de aCl lgG naqueles com ulcerações.

Por que esses anticorpos aparecem nessa situação, como se formam e qual o seu papel na etiologia do processo são especulações que, se adequadamente esclarecidas poderão abrir novas perspectivas para tratamento desses pacientes. Frente a essa situação, o estudo das anticardiolipinas nas diferentes formas de úlcera de perna torna-se importante.

O presente estudo foi delineado com os objetivos de verificar a prevalência de aCls em pacientes com diferentes tipos de úlcera de perna da população local e com a finalidade de caracterizar clinicamente uma úlcera anticardiolipina positiva.

\section{MÉTODOS}

Este estudo foi aprovado pelo Comitê de Ética em Pesquisa da Sociedade Evangélica Beneficente de Curitiba e tendo sido obtido o consentimento livre e esclarecido de todos os seus participantes ( $n^{\circ} 2431$ ).

Estudaram-se 151 pacientes com úlcera de perna (81 de causa venosa, 50 diabética e 30 arterial), aqui identificados como grupo úlcera e admitidos no estudo por ordem de chegada à consulta do ambulatório de Cirurgia Vascular do Hospital Universitário Evangélico de Curitiba e 150 controles pareados para sexo e idade, identificados como grupo controle. Foram considerados elegíveis para o estudo pacientes de ambos os sexos com úlcera de perna em atividade por pelo menos seis semanas.

Para inclusão no grupo úlcera venosa, os pacientes deveriam ter varizes de membros inferiores, história de trombose venosa, edema vespertino, dermatite ocre e/ou lipoesclerodermatose. Para inclusão no grupo de úlcera diabética, deveriam ter história pregressa de diabete melito comprovada ou glicose de jejum acima de $126 \mathrm{mg} / \mathrm{dL}$ ou, ainda, glicemia $2 \mathrm{~h}$ pós-prandial ou randômica acima de $200 \mathrm{mg} / \mathrm{dL}^{5}$. Para inclusão no grupo de úlcera arterial, deveriam apresentar diminuição de pulsos periféricos ou razão = 0.7 entre pressão sistólica de membro inferior e superior ${ }^{6}$.

Excluíram-se indivíduos em uso de medicamentos e drogas sabidamente implicados na positividade dos anticorpos antifosfolípides (anti-TNF- $\alpha$, diuréticos tiazídicos, propranolol, clorpromazina, interferon $\gamma$, amoxacilina, procainamida e (cocaína $)^{7}$; pacientes com doença neoplásica ou doença associada com a presença desses anticorpos; presença de outras formas de infecção, que não a em úlcera de perna e pacientes com a possibilidade de úlceras mistas que não permitissem a inclusão do paciente em um grupo definido, exceto pelos casos de pacientes com úlceras diabéticas onde era permitida associação do componente arterial e neuropático.

Pacientes com úlceras de perna foram submetidos a questionário para obtenção de dados demográficos, tempo de doença, uso de tabaco, história pregressa de trombose venosa profunda e grau de dor atribuído à úlcera pela escala visual analógica, onde era atribuído zero à ausência de dor e 10 ao maior grau de dor possível. Realizou-se exame físico com atenção ao número de feridas abertas e ao tamanho da área ulcerada (obtido multiplicando-se os diâmetros longitudinal e vertical da mesma) ${ }^{8}$. Em casos de mais de uma úlcera, os valores obtidos isoladamente eram somadas entre si.

Pacientes do grupo úlcera e grupo controle foram submetidos à coleta de sangue venoso para pesquisa de aCls IgG e IgM pelo método de Elisa (Euroimmun, Lübeck, Germany) seguindo-se a técnica recomendada pelo manufaturador.

Os dados obtidos foram coletados em planilhas sendo submetidos a estudos por tabelas de frequência e contingência. Para cálculo de associação de dados nominais utilizou-se o teste de Fisher ou do qui-quadrado de acordo com a amostra analisada. Para cálculo de associação de dados contínuos utilizaram-se os teste de MannWhitney e Krukall-Wallis. Para cálculo de correlação utilizou-se o teste de Spearmann. Os testes foram realizados com auxílio do software GraphPad Prism $₫$ adotando-se o nível de significância de 5\%.

\section{RESULTADOS}

Os dados referentes ao pareamento da amostra encontram-se resumidos na tabela 1.

Encontrou-se a presença de anticorpos anticardiolipina em níveis acima de 10U/mL em dois (1.3\%) pacientes do grupo controle e ambos tinham anticorpos do tipo lgG em baixos títulos (fracamente positivos): 17.8 GPL $\mathrm{mL}$ e $15 \mathrm{GPL} / \mathrm{mL}$.

$\mathrm{Na}$ amostra de pacientes com úlceras de pernas encontraram-se níveis acima de $10 \mathrm{U} / \mathrm{mL}$ em 12 pacientes $(7.2 \%)$ sendo os valores de aCl $\lg$ G entre 10.2 e $47.9 \mathrm{GPL} / \mathrm{mL}$ (média de $18.3 \pm 13.6 \mathrm{GPL} / \mathrm{ml}$ e os valores de aCl IgM entre 11.2 e $65.7 \mathrm{MPL} / \mathrm{mL}$ (média de $33.1 \pm$ 21.9 MPL/ml).

Tabela 1 - Pareamento da amostra de pacientes do grupo úlcera e do controle.

\begin{tabular}{lccc}
\hline & Úlcera de perna & Controle & $p$ \\
& $n=151$ & $n=150$ & $0,07(*)$ \\
Gênero (feminino:masculino) & $76: 75$ & $99: 51$ & $0,73(* *)$ \\
Idade média (em anos) & $60,7 \pm 12,0$ & $61,2 \pm 9,9$ & $(*)$ \\
\hline
\end{tabular}


Comparando-se a positividade de anticorpos anticardiolipina entre a população controle e a população do grupo úlcera obteve-se $\mathrm{p}=0.01$ (Fisher).

Dos pacientes do grupo úlcera e anticorpos anticardiolipinas positivos, um tinha úlcera arterial (4.7\% da amostra de pacientes com úlceras arteriais); seis tinham úlcera venosa $(7.5 \%$ dos pacientes com úlcera venosa) e cinco tinham úlcera diabética ( $10 \%$ da amostra de pacientes com úlcera diabética). Comparando-se a positividade dos anticorpos entre grupo controle e úlceras venosas obteve-se $p=0.02$ (Fisher); entre controle e úlceras diabéticas, $p=0,01$ (Fisher) e entre controle e úlceras arteriais, $\mathrm{p}=0.61$; (Fisher).

Quando os pacientes do grupo úlcera positivos para anticorpos anticardiolipinas foram comparados com aqueles com úlcera, mas negativos para esse auto anticorpos, obtiveram-se os dados resumidos na tabela 2.

\section{DISCUSSÂO}

O presente estudo demonstrou que, em pacientes com úlcera de perna, existe aumento significativo dos auto-anticorpos anticardiolipinas $\lg \mathrm{G}$ e $\lg \mathrm{M}$ em relação à população controle. Isto acontece tanto nos portadores de úlceras venosas como nas úlceras diabéticas, mas não em casos de úlceras arteriais.

O aumento desses auto-anticorpos em úlceras de etiologia venosa e de etiologia diabética está concorde com dados da literatura embora a porcentagem de positividade encontrada no presente estudo tenha sido menor do que o constatado por outros autores. Mackenzie et al. ${ }^{2}$, estudando 115 pacientes observaram anticardiolipinas positivas em 49 (42\% dos casos de úlceras venosas e $43,4 \%$ de úlceras arteriais). Alagözlü et al. ${ }^{4}$, encontrou prevalência de $34,3 \%$ de positividade em indivíduos com úlceras contra $8,6 \%$ da população controle. Alcaraz et al. ${ }^{9}$, ao estudar 48 casos de pacientes com úlceras observou presença de anticorpo antifosfolípides em $44,4 \%$ dos casos de úlcera venosa e $75 \%$ dos casos de úlceras arteriais. Na presente análise, embora a presença de anticorpos anticardiolipina estivesse aumentada em relação à população geral, detectou-se prevalência muito mais baixa de positividade para esses anticorpos: 4,76\% da amostra de úlceras arteriais; 7,5\% dos casos de úlcera venosa e $10 \%$ dos casos de úlcera por diabetes. A menor prevalência desta amostra pode ser explicada em termos de background genético de nossa população, o qual influi no aparecimento de fenômenos de auto-imunidade ${ }^{10}$. Diminuição no achado de anticorpos positivos na população controle suporta essa hipótese. No caso dos anticorpos antifosfolípides, esse componente genético tem sido identificado nos genes MHC classe 2 como o HLADR 4, HLA-DR 7, HLA-DRW 53 e HLA-DQB1*0302 ${ }^{11,12 .}$

Outro dado que pode ter interferido com o grau de positividade dos resultados é o teste feito para pesquisa dos anticorpos. Embora todos tenham usado pesquisa pelo método de ELISA, a origem do material utilizado não está explicitada nos trabalhos. Mackenzie et $a^{2}$ associou a pesquisa de aCl IgA à dos aCls lg e e lgM e na série descrita por Alcaraz et al. ${ }^{9}$ a pesquisa feita foi de anticorpos antifosfolipides em geral. Nessa última situação, vários outros anticorpos antifosfolípides, além dos anticorpos anticardiolipinas podem contribuir para a positividade encontrada.

Alcaraz et al. ${ }^{9}$ e Mackenzie et al..$^{2}$ encontraram aumento de prevalência de anticardiolipinas em pacientes com úlceras arteriais, o que não foi verificado nesta amostra. Tal discrepância pode ser explicada pelo fato de que úlceras arteriais podem ter múltiplas etiologias, incluindose vasculites, que, por serem doenças associadas à disfunção do sistema imune, cursam com maior prevalência de anticorpos anticardiolipina. Na amostra presentemente estudada, tais pacientes foram excluídos.

Diante dos dados obtidos, a grande pergunta que se faz é se a presença desses auto-anticorpos pode ser considerada causa ou consequência da úlcera. Considerando-se a primeira opção, ou seja, a de que esses autoanticorpos possam estar implicados na etiologia da úlcera de perna, a primeira explicação existente é a de que as anticardiolipinas, sendo anticorpos trombogênicos, causariam úlceras secundárias a episódios de trombose venosa profunda. Um estudo de 223 pacientes com trombose venosa sintomática mostrou que, em 13 anos de seguimento, $39 \%$ deles desenvolveram insuficiência venosa crônica e

Tabela 2 - Comparação de características clínicas e laboratoriais entre pacientes do grupo úlcera com e sem anticorpos anticardiolipinas (aCls).

\begin{tabular}{|c|c|c|c|}
\hline Variável & $\begin{array}{c}\text { aCl positivas } \\
n=12\end{array}$ & $\begin{array}{c}\text { aCl negativas } \\
n=139\end{array}$ & $P$ \\
\hline Gênero (masculino:feminino) & $6: 6$ & $69: 70$ & $0,98(*)$ \\
\hline Tamanho médio em $\mathrm{cm}^{2}$ & $68,5 \pm 114,1$ & $41,1 \pm 75,2$ & $0,50(* *)$ \\
\hline Dor (EVA média \#) & $6,0 \pm 3,8$ & $6,4 \pm 3,9$ & $0,67(* *)$ \\
\hline Número médio de úlceras/paciente & $1,4 \pm 1,1$ & $1,7 \pm 1,0$ & $0,38\left(^{*}\right)$ \\
\hline Tempo médio de duração de doença (meses) & $88,6 \pm 203,1$ & $55,8 \pm 98,3$ & $0,59(* *)$ \\
\hline Trombose venosa prévia & $(8,3 \%)$ & $(18,7 \%)$ & $0,69(\#)$ \\
\hline Exposto ao fumo & $(83,3 \%)$ & $(42,4 \%)$ & $0,012(\#)$ \\
\hline
\end{tabular}

EVA= escala visual analógica

n=número da amostra

(*) Teste de Fisher

(*) Qui-quadrado

(**) Mann Whitney 
em $10 \%$ apareceram úlceras venosas ${ }^{13}$. Por outro lado, em uma série de 48 pacientes com úlceras de perna nos quais $46 \%$ eram positivos para anticorpos antifosfolípides, a maioria dos pacientes estudados não apresentava clínica ou sinais de síndrome pós-flebítica ${ }^{9}$. No presente estudo, também não se observou maior prevalência de anticorpos anticardiolipinas em pacientes com história anterior de trombose venosa. Além disso, o argumento de que a formação da úlcera é secundária à trombose venosa profunda só seria válido para úlceras venosas, não explicando o aumento de anticorpos anticardiolipina constatado em úlceras diabéticas.

Uma segunda possibilidade seria a de que esses auto-anticorpos colaborassem através de formação de microtrombos mediante aumento na agregação plaquetária e, ao promoverem trombose de microcirculação, aumentassem a área de perda de viabilidade do tecido. Nesta hipótese os auto-anticorpos poderiam não só iniciar o processo, mas contribuir para a sua perpetuação. Esse é o mecanismo considerado como o mais provável para o aparecimento de úlceras em pacientes com a forma primária da síndrome do anticorpo antifosfolípide ${ }^{14}$.

Também é possível que o aparecimento desses auto-anticorpos seja secundário à úlcera. Uma vez estabelecida lesão tecidual, existe liberação de enzimas proteolíticas que danificam a parede endotelial, expondo antígenos fosfolipídicos ao sistema imune. Esses antígenos induziriam a formação de auto-anticorpos ${ }^{9}$. Dentro dessa possibilidade, eles funcionariam como marcadores da úlcera sem terem papel algum no seu aparecimento. De maneira contrária Fink et al. ${ }^{15}$ conseguiram detectar a presença desses anticorpos em pacientes com insuficiência venosa sem úlceras cutâneas. mostrando que eles devem estar presentes no organismo do individuo afetado antes do desenvolvimento da lesão em perna.

Uma última hipótese para explicar a formação desses auto-anticorpos seria a de que a infecção no local da úlcera fosse o gatilho para o seu aparecimento ${ }^{16,17}$. Determinados microorganismos (bacterianos e virais) partilham a mesma sequência de aminoácidos encontrada em alguns antifosfolípideos e podem causar reação cruzada do tipo mimetismo molecular (17) Notadamente os anticorpos antifosfolípides associados à infecção não costumam ter atividade trombogênica e, nessa situação, poderiam não participar da gênese do processo ulceroso ${ }^{18}$. Um fato a ser levado em conta contra esse argumento é o de que as úlceras arteriais, igualmente sujeitas a infecções secundárias, não apresentaram aumento da prevalência de anticorpos anticardiolipinas.

Através das variáveis clínicas estudadas, não foi possível detectar algum indício clínico de que os pacientes eram portadores de anticorpos anticardiolipina. O número de tromboses venosas profundas prévias, tamanho da úlcera, grau de dor medido pela escala visual analógica, número de feridas e tempo de doença foram semelhantes nos grupos de úlcera de perna com e sem o auto-anticorpo. A única distinção observada foi a de que usuários de tabaco tinham mais auto-anticorpos do que os não usuários. O fumo é um elemento predisponente de fenômenos de auto-imunidade, como por exemplo, a presença de fator reumatóide, e pode estar atuando como um elemento favorecedor do aparecimento das anticardiolipinas ${ }^{19}$.

Os achados do presente estudo sugerem a possibilidade de inovações no tratamento das úlceras de perna. Manifestações clínicas secundárias à presença de anticorpos antifosfolípides reconhecidamente respondem ao uso de anticoagulantes e antimaláricos ${ }^{18,19}$. Anticoagulantes são medicamentos de uso complexo, com muitos efeitos colaterais e que exigem monitoramento constante. Entretanto os antimaláricos (cloroquina e hidroxicloroquina) são drogas com propriedades antiagregantes de plaquetas, de fácil utilização, bem toleradas e de baixo custo ${ }^{20,21}$. Têm sido utilizadas em casos de lúpus com SAF secundária e em casos da SAF primária em pacientes grávidas com abortamento de repetição ${ }^{22}$. Abre-se assim, uma nova possibilidade terapêutica, caso esses anticorpos realmente estejam implicados na etiopatogenia do processo. Em situação nosológica com tantas dificuldades de tratamento e com tantas repercussões sociais, novas opções de intervenção medicamentosa são recebidas com esperança.

Concluindo pode-se dizer que existe aumento de prevalência de anticorpos anticardiolipina em úlceras de perna de etiologia venosa e diabética mas não nas arteriais e que as características clínicas e demográficas dos pacientes com úlceras com anticardiolipinas positivas não auxiliam na identificação da presença desse auto-anticorpo.

\title{
A B S T R A C T
}

\begin{abstract}
Objective: To verify the prevalence of IgG and IgM anticardiolipin antibodies in patients with leg ulcer (venous, arterial and diabetic) and if these patients can be identified by clinical means. Methods: A serie of 151 patients with leg ulcer (81 venous, 50 diabetic and 20 arterial ulcers) and 150 controls were studied. In both groups it was searched the presence of IgG and IgM anticardiolipin by the ELISA method. In the leg ulcer group demographic data were obtained, data on the leg ulcer size and number as well as pain severity measured by an analogical visual scale. In statistic analysis, the adopted significance was of 5\%. Results: It was found an anticardiolipin prevalence of $7.2 \%(n=12)$ in the leg ulcers group and of $1.3 \%(n=2)$ in the control group ( $p=0.01)$. Comparing the different ulcer types with control population, it was found that there was an increase in anticardiolipin antibodies in venous $(p=0.02)$, and diabetic $(p=0.01)$ but not in arterial ulcers $(p=0.31)$. Leg ulcer patients with anticardiolipin did not differ from those without it in gender $(p=0.98)$; ulcer size $(p=0.6)$; pain severity $(p=0.67)$, mean number of ulcers $(p=0.38)$, mean disease duration time $(p=0.59)$ and previous history of venous thrombosis $(p=0.69)$. Conclusion: There is an increased prevalence of anticardiolipin antibodies in patients with venous leg ulcers and diabetic ulcers but not in those of arterial origin. Clinical characteristics of ulcers do not help in the identification of these patients.
\end{abstract}

Key words: Leg ulcer. Venous insufficiency. Skin ulcer. Diabetic foot. Antibodies, anticardiolipin. 


\section{REFERENCIAS}

1. Abbade LPF, Lastoria S. Abordagem de pacientes com úlcera da perna de etiologia venosa. An Bras Dermatol. 2006; 81(6): 509-22.

2. Mackenzie RK, Ludlam CA, Ruckley CY, Allan PL, Burns P, Bradbury AW. The prevalence of trombophilia in patients with chronic venous leg ulceration. J Vasc Surg. 2002; 35(4):718-22.

3. Petri M. Clinical and management aspects of antiphospholipid antibody syndrome. In: Wallace DJ, Hahn BH, editors. Dubois' lupus erythematosus. Philadelphia: Lippincott Williams \& Wilkins ; 2007. p. 1262-97.

4. Alagözlü H, Bakici Z, Gültekin F, Yildirim B, Sezer H. Anticardiolipin antibody positivity in diabetic patients with and without diabetic foot. J Diabetes Complications. 2002; 16(2): 172-5.

5. Culloch D. Screening for diabetes mellitus [database on the Internet]. Waltham (MA): UpToDate Patient Preview. c2008. [updated 2008 Oct 20; cited 2008 Nov 12]. Available from: http:// www.uptodate.com/home /index.html.

6. Grey JE, Enoch S, Harding KG. ABC of wound healing: venous and arterial leg ulcers. Student BMJ. 2006; 14: 140-3.

7. Goldberg SN, Conti-Kelly AM, Greco TP. A family study of anticardiolipin antibodies and associated clinical conditions. Am J Med. 1995: 98(5): 473-9.

8. Kantor J, Margolis DJ. Efficacy and prognostic values of simple wound measurements. Arch Dermatol. 1998; 134(12): 1571-4

9. Alcaraz I, Lafreve I, Wiart T, Lafon C, Forzy G, Modiano P. Leg ulcers and antiphospholipid antibodies: prospective study of 48 cases. Ann Dermatol Venereol. 1999; 126(4): 313-6.

10. Hunter DJ. Gene-environment interactions in human diseases. Nat Rev Genet. 2005; 6(4): 287-98.

11. Domenico Sebastiani G, Minisola G, Galeazzi M. HLA class II alleles and genetic predisposition in the antiphospholipid syndrome. Autoimmun Rev. 2003; 2(6): 387-94.

12. Goldstein R, Moulds JM, Smith CD, Sengar DP. MHC studies of the primary antiphospholipid antibody syndrome and of antiphospholipid antibodies in systemic lupus erythematosus. J Rheumatol. 1996; 23(7): 1173-9

13. Walker N, Rodgers A, Birchall N, Norton R, MacMahon S. Leg ulceration as long term complication of deep vein thrombosis. J Vas Surg. 2003; 38(6): 1331-5.
14. Weistein S, Piette W. Cutaneous manifestations of antiphospholipid antibody syndrome. Hematol Oncol Clin North Am. 2008; 22(1): 67-77.

15. Fink AM, Kottas-Heldenberg A, Bayer PM, Bednar R, Steiner A. Lupus anticoagulant in patients with chronic venous insufficiency. Acta Derm Venereol. 2003; 83(4): 287-9.

16. Amin NM. Antiphospholipid syndromes in infectious diseases. Hematol Oncol Clin N Am. 2008; 22: 131-43.

17. Shoenfeld Y, Blank M, Cervera R, Font J, Raschi E, Meroni PL. Infectious origin of the antiphospholipid syndrome. Ann Rheum Dis. 2006; 65(1): 2-6.

18. Gezer S. Antiphospholipid syndrome. Dis Month.2003; 49(12): 69642

19. Harel-Meir M, Sherer $Y$, Shoenfeld $Y$. Tobacco smoking and autoimmune rheumatic diseases. Nat Clin Pract Rheumatol. 2007; 3(12): 707-15

20. Davis JC, Klippel JH. Antimalarials and immunossupressive therapies. In: Lahita RG, editor. Systemic lupus erythematosus. San Diego: Elsevier; 2004. p. 1273-93.

21. Rand JH, Wu XX, Quinn AS, Chen PP, Hathcock JJ, Taatjes DJ. Hydroxychloroquine directly reduces the binding of antiphospholipid antibody-beta2-glycoprotein I complexes to phospholipids bilayers. Blood. 2008; 11295): 1687-95. Epub 2008 Jun 24.

22. Wallace DJ. Antimalarial Therapies. In: Wallace DJ, Hahn B, editors). Dubois' lupus erythematosus. Philadelphia: Linpicott Willians \& Wilkins; 2007. p. 1152-74.

Recebido em 05/10/2008

Aceito para publicação em 07/12/2008

Conflito de interesse: nenhum

Fonte de financiamento: nenhuma

\section{Como citar este artigo:}

Skare TL, Ribas CAP, Malafaia O, Ribas Filho JM, Nassif PAN, Nascimento $\mathrm{MM}$, Fonseca VRC. Anticorpos anticardiolipinas em úlceras de perna. Rev Col Bras Cir. [periódico na Internet] 2009; 36(2). Disponível em URL: http://www.scielo.br/rcbc

\section{Endereço para correspondência:}

Thelma L Skare

E-mail tskare@onda.com.br 